\title{
STRUCTURE/PROPERTY RELATIONSHIP
}

IFM, Università di Torino, Italy. E-mail:

Bartolomeo.civalleri@unito.it

The aim of this work is the study of weak intermolecular interactions in molecular crystals, by both diffraction methods and $a b$ initio calculations using the new version of the CRYSTAL [1] program, which is designed to treat infinite periodic systems. Two molecular systems were chosen: i) formamide [2]: each molecule is linked to three other molecules by two types of hydrogen bonds; ii) boric acid [3]: each molecule forms six almost equivalent hydrogen bonds with three neighbouring molecules. The CRYSTAL03 calculations were carried out employing the HF and DFT (B3LYP) methods with the 6$31 \mathrm{G}(\mathrm{d}, \mathrm{p})$ basis set, also using the new geometry optimisation options. The electron density, the electrostatic potential, the binding energies and the structure factors were derived. In formamide the cooperative effects of packing on the hydrogen bond interactions leading to the formation of linear chains and on those connecting the chains were analyzed. Hydrogen bonded molecules of boric acid form layers held together by weak B---O interactions, which may play a role in dictating the inter-layer packing. The comparison of the experimental and theoretical results and the most recent results obtained using the geometry optimisation facilities in CRYSTALO3 will be presented.

[1] Saunders V.R., et al., CRYSTAL03, www.crystal.unito.it [2] Stevens E.D., Acta Cryst., 1978, B34, 544. [3] Gajhede M., Larsen S., Rettrup S., Acta Cryst., B42, 545,1986 .

Keywords: hydrogen bond, weak interactions, ab-initio calculations

\section{P.08.08.16}

Acta Cryst. (2005). A61, C332

Orientations of Axially Coordinated Ligands in Model Systems of Cytochromes

Vesna B. Medaković, Miloš K. Milčić, Aleksandra A. Rakić, Snežana D. Zarić, Department of Chemistry, University of Belgrade, Studentski trg 16, 11001 Belgrade, Serbia and Montenegro. E-mail: vesnam@chem.bg.ac.yu

Many properties of cytochromes and model systems depend on orientations of axial ligands. In this work we elucidated role of substituents of porphyrin on orientation of axial ligands in model systems of cytochromes. The orientations of axially coordinated imidozoles and pyridines in crystal structures of model systems of cytochromes were analyzed and data were compared with previous quantum-chemical calculations.

The results show that eight ethyl groups on porphyrin ring strongly favor parallel orientation, hence, in all these complexes axial ligands, pyridines or imidazoles, are mutually parallel. Four phenyl or mesityl groups at meso-carbons also favor parallel orientation but less strong. Hence, in most of the bis-imidazole complexes orientation is parallel, while in bis-pyridine complexes orientation of pyridines depends on oxidation state of Fe.

In $\mathrm{Fe}(\mathrm{II})$ complexes orientation is parallel, in $\mathrm{Fe}(\mathrm{III})$ it is orthogonal. In $\mathrm{Fe}$ (III) complexes influence of the interaction of pyridine with porphyrin ring, dominates over influence of phenyl or mesityl groups on porphyrin ring, and the orientation is parallel. Namely, by previous quantum chemical calculations it was shown that in bis-pyridine $\mathrm{Fe}(\mathrm{III})$ porphyrinato complexes without substituents orthogonal orientation is favored by $16 \mathrm{kcal} / \mathrm{mol}$.

Keywords: ligands, porphyrins, cytochromes

\section{P.08.08.17}

Acta Cryst. (2005). A61, C332

$\mathrm{CH} / \pi$ Interactions between Chelate and Phenyl Rings in Acetylacetonato Complexes

Miloš K. Milčić, Vesna B. Medaković, Nenad Juranić, Snežana D. Zarić, Department of Chemistry, University of Belgrade, Studentski trg 16, 11001 Belgrade, Serbia and Montenegro. E-mail: mmilcic@chem.bg.ac.yu

By coordinating to metal atom with acetylacetonato ligand makes planar chelate ring, with delocalized bonds. Hence, coordinated acetylacetonato ligand could be involved in $\mathrm{CH} / \pi$ interactions with phenyl ring in two ways, as hydrogen atom donor, or as hydrogen atom aceptor. In first case hydrogen atoms of acetylacetonato ligand could make MLAC $\pi$ interactions with phenyl ring. Acetylacetonato ligand has negative charge, but by coordinating to metal cation partial positive charge is transferred from the metal cation to the ligand. If enough positive charge is transferred hydrogen atoms of acetylacetonato ligand will get enough positive charge to be involved in MLAC $\pi$ interactions. In second type of interactions phenyl ring and chelate ring change roles; phenyl ring is hydrogen atom donor whereas chelate ring with delocalised $\pi$-system is hydrogen atom acceptor.

Here we report on $\mathrm{CH} / \pi$ interactions between acetylacetonato chelate rings and phenyl rings in acetylacetonato complexes. The results were obtained by searching and analyzing crystal structures in Cambridge Structural Database (CSD) and by quantum chemical calculations. Dependence of $\mathrm{CH} / \pi$ interactions on delocalization in chelate rings that is connected with type of metal in the ring was studied. To the best of our knowledge this is the first time that influence of metal in a chelate ring on $\mathrm{CH} / \pi$ interactions in metal complexes was studied.

Keywords: $\mathrm{CH} / \pi$ interactions, DFT, chelates

\section{P.08.09.1}

Acta Cryst. (2005). A61, C332

Structural Characterisation of $p$-semiquinone Radical in a Crystal: X-ray Structure and EPR Evidence

$\underline{\text { Krešimir Molčanov }}^{\mathrm{a}}$, Biserka kojić-Prodića ${ }^{\mathrm{a}}$, Mario Roboz ${ }^{\mathrm{b}}$, Božidar S. Grabarić $^{\mathrm{b}}$, Rudjer Bošković Institute, Zagreb, Coratia. ${ }^{\mathrm{b}}$ Faculty of Food Technology and Biotechnology, University of Zagreb, Croatia. E-mail:kojic@irb.hr

In membrane-located proteins, quinone system plays a significant role in electron-transfer reactions. The described work illustrates that semiquinone radical is stabilized in the solid state.

Thin dark-red plate-like crystals of $p$-semiquinone radical were grown by evaporation of mildly alkaline, saturated water solution of hydroquinone. Although stable in air, larger single crystals decay after ca. $20 \mathrm{~h}$ exposure to X-rays or UV radiation producing amorphous yellow substance identified as a mixture of quinone and quinhydrone.

Solid-state electronic paramagnetic resonance spectra of crystalline $p$-semiquinone detected its paramagnetic propetries revealing four symmetrically equivalent protons.

Crystal strucure was determined at 100 and $150 \mathrm{~K}$ (monoclinic, space group P $21 / \mathrm{c}, \mathrm{a}=3.78 \AA, \mathrm{b}=5.98 \AA, \mathrm{c}=10.79 \AA, \beta=90.66^{\circ}$ ). In both of them, $p$-semiquinone molecule is centrosymmetric (four protons are, therefore, equivalent), with C-O bond length of $1.295 \AA$, corresponding to bond order of 1.5. Molecules are hydrogen bonded into infinite chains $(\mathrm{O}-\mathrm{H} \cdots \mathrm{O}$ distance of $2.70 \AA$ with the proton disordered between two oxygen atoms. This packing is very similar to that of quinhydrone; the unit cell can be transformed into a half of the unit cell of quinhydrone.

Keywords: radical, $p$-semiquinone, EPR

\section{P.08.09.2}

Acta Cryst. (2005). A61, C332-C333

Crystal Structure and Synthesis of New Trinuclear 3d-metal Trifluoroacetates

Alexandra O. Tokareva, Denis S. Tereschenko, Alexander I. Boltalin, Sergey I. Troyanov, Departament of Chemistry, Moscow State University. E-mail: tokareva_a2002@mail.ru

Anhydrous acid trinuclear trifluoroacetates of divalent metals $\left[\mathrm{M}_{3}\left(\mathrm{CF}_{3} \mathrm{COO}\right)_{6}\left(\mathrm{CF}_{3} \mathrm{COOH}\right)_{6}\right] \mathrm{CF}_{3} \mathrm{COOH}$ where $\mathrm{M}=\mathrm{Ni}$ (I) and $\mathrm{Co}$ (II), and partially hydrated nickel trifluoroacetate $\left[\mathrm{Ni}_{3}\left(\mathrm{CF}_{3} \mathrm{COO}\right)_{4}\left(\mathrm{CF}_{3} \mathrm{COOH}\right)_{4}\left(\mathrm{H}_{2} \mathrm{O}\right)_{4}\right]\left(\mathrm{CF}_{3} \mathrm{COOH}\right)_{2}$ (III) were synthesized and studied by $\mathrm{X}$-ray diffraction. Compounds I and II were obtained by crystallization from solutions of $\mathrm{Ni}\left(\mathrm{CF}_{3} \mathrm{COO}\right)_{2} \cdot 4 \mathrm{H}_{2} \mathrm{O}$ (I), $\mathrm{Co}\left(\mathrm{CF}_{3} \mathrm{COO}\right)_{2} \cdot 4 \mathrm{H}_{2} \mathrm{O}$ (II) in trifluoroacetic anhydride in the presence of phosphoric anhydride as the drying agent. Compound I crystallizes in trigonal system, space group. $R \overline{3}$, $\mathrm{Z}=27, \mathrm{a}=13.307(2), \mathrm{c}=53.13(1) \AA, \mathrm{V}=8148(2) \AA^{3}, \mathrm{R}_{1}=0.1112$. The structure is molecular; trinuclear linear unit is formed by three metal 